\title{
COMPLICATIONS OF ORGANOPHOSPHORUS POISONING.
}

1. MBBS, FCPS (Med)

Senior Registrar

Sheikh Zaid Medical College Rahim Yar Khan.

2. MBBS

Post Graduate Resident

Sheikh Zaid Medical College Rahim Yar Khan.

3. MBBS, FCPS (Med)

Assistant Professor

Sheikh Zaid Medical College Rahim Yar Khan.

4. MBBS, M.Phil (Pharmacology) Associate Professor Pharmacology Sheikh Zaid Medical College Rahim Yar Khan.

5. FCPS (Medicine)

Assistant Professor Pharmacology Sheikh Zaid Medical College Rahim Yar Khan.

6. MBBS, M.Phil (Pathology) Professor Microbiology

Sheikh Zaid Medical College Rahim Yar Khan.

Correspondence Address:

Dr. Shoaib Akhtar

Sheikh Zaid Medical College Rahim Yar Khan.

shoaib.akhtar161dr@gmail.com

Article received on:

16/08/2019

Accepted for publication:

$21 / 10 / 2019$

\section{INTRODUCTION}

Organophosphorus compounds are toxic substances which are quite often used to kill the insects and bugs in the agricultural areas and the cases with its toxicity are well reported. This toxicity can be due to either accidental exposure while spraying this compound and absorption occurs via skin or can be used with suicidal intent. The suicidal attempts are far higher than accidental exposure and pose a great burden not only in terms of mortality but also great morbidity. The suicidal attempts has increased by $60 \%$ from the last fifty years. ${ }^{1-2}$

There are number of chemical subgroups in this poising comprising Malathion, Fenthion, Parathion etc. The mechanism involved in its toxicity is by inhibition of carboxyl ester hydrolases, particularly acetyl cholinesterase; hence leads to accumulation of acetylcholine (ACh). Other mechanisms involved are increased sympathetic and parasympathetic activity, hypoxia, deranged electrolytes, acidosis, and direct toxicity to the heart and kidneys..$^{3-4}$ In contrast to OP poisoning, the treatment done with atropine may also be indulged in further arrhythmias. ${ }^{5}$ Few of such complications can be short term while the other can be life threatening.

The clinical manifestations of OP are usually subdivided into three groups i.e. primary, delayed and intermediate syndromes. ${ }^{6-7}$ There is diverse manifestation of cardiac, renal, respiratory, neurological, GI, neuromuscular involvement. ${ }^{8-10}$ 
Renal failure can be due to direct toxicity or due to other manifestation of pre renal failure in the form of parasympathetic stimulation or cardiac disease. ${ }^{11}$

Cardiac symptoms can be manifested in three phases. First of all there is an increased sympathetic activity. Secondly, there is prolonged parasympathetic stimulation and thirdly QT prolongation, which can induce fatal ventricular arrhythmias. $^{12}$

\section{MATERIAL \& METHODS}

This study was carried out Department of Medicine, Sheikh Zayed hospital, Rahim Yar khan from the period of January 2015 to December 2015. All adult cases with documented history of Organophosphorus poising either transdermally or oral ingestion with either accidental or intentional intake were included. The cases with previous history of DM, HTN, renal failure, cardiac failure and neurologic deficit were excluded from the study. The poisoning was confirmed by history of exposure either from the patients or their attendants and signs of its toxicity with constricted pupil, excessive lacrimation and crepitations in the chest. The cases then underwent ECG and renal function tests in the form of urea and creatinine. The abnormalities in ECG were documented and the urea level more than $30 \mathrm{mg} / \mathrm{dl}$ and creatinine more than $1.5 \mathrm{mg} / \mathrm{dl}$ was labeled as acute renal failure.

This was a cross sectional study. The data was entered on SPSS version 17. The sociodemographic data like age, weight, gender and other data like duration of Organophosphorus taken, routine and intention of OP taken was collected. The mean and standard deviation were calculated for age, weight, duration of OP taken. Frequencies and percentages were calculated for gender, intention and route of OP taken and type and pattern of complication developed regarding cardiac or renal complication. Chi square test was used to see for significance and $p$ value of $\leq$ 0.05 was taken as significant.

\section{RESULTS}

In this study there were 100 cases, out of which 58 (58\%) were females and 42 (42\%) males. The mean age was $22.58 \pm 48$ years. The mean duration taken to present with OP was $7 \pm 0.24$ hours (Table-I). Out of 100 cases $82(82 \%)$ had oral intake as compared to $18(18 \%)$ transdermal absorption. All 18 transdermal absorption cases had accidental exposure while out of 82 oral intakes 5 had accidental intake and 77 suicidal attempts. Out of 100 cases complications were seen in 35 (35\%) cases out of which 6 had ARF and 29 had cardiac complication (Figure-1). Among these 29 cases with cardiac complication premature ventricular contraction (PVCs) was the most common seen in 13 cases, 7 had bradycardia, 6 had prolonged QT and remaining 3 observed ventricular tachycardia (VT) as in Figure-2. Among all the cases, renal failure was seen more in females as compared to males where it affected 4 females and 2 males with $p=$ 0.13 . There was no significant difference in terms of age groups with ARF $(p=0.54)$. Renal failure was most common among oral intake and with accidental intent; however this difference was also not significant with $p=0.13 \& 0.10$. However, a near significance was seen with duration of OP taken more than 4 hours $(p=0.07)$ as in Table-II. Cardiac complications were also more common in females affecting 19 females as compared to 10 males $(p=0.17)$. There was no significant difference in age groups with respect to cardiac complications (0.78). Cardiac complications were significantly higher in groups with oral intake and with suicidal intention with $p=0.001$ and 0.001 (Table-III).

\begin{tabular}{|l|c|c|}
\hline \multicolumn{1}{|l|}{} & Mean & Range \\
\hline Age & $22.58 \pm 48$ & $14-52$ years \\
\hline Weight & $40 \pm 3.35$ & $32-81 \mathrm{~kg}$ \\
\hline Duration of OP taken & $7 \pm 0.24$ & $3-14$ hours \\
\hline \multicolumn{2}{|c|}{ Table-I. Study variables $\mathbf{n}=\mathbf{1 0 0 .}$} \\
\hline
\end{tabular}




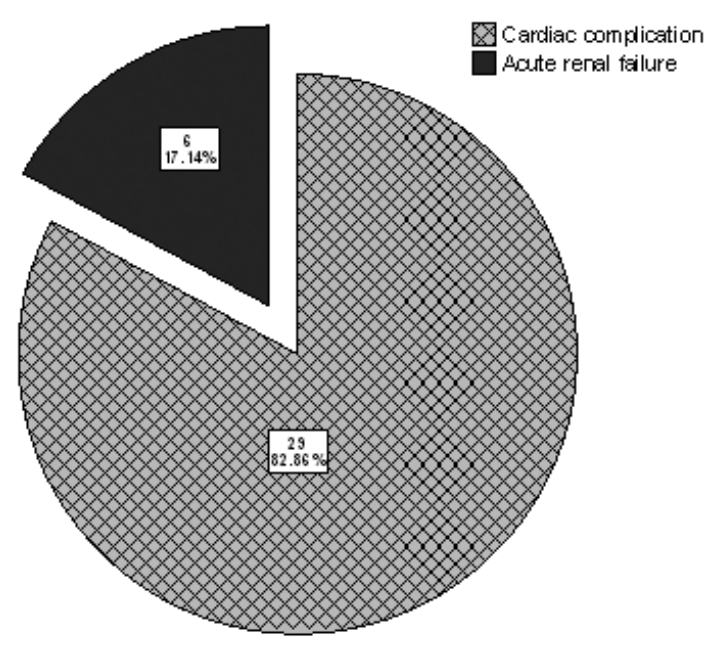

Figure-1. Complication of OP $n=35$.

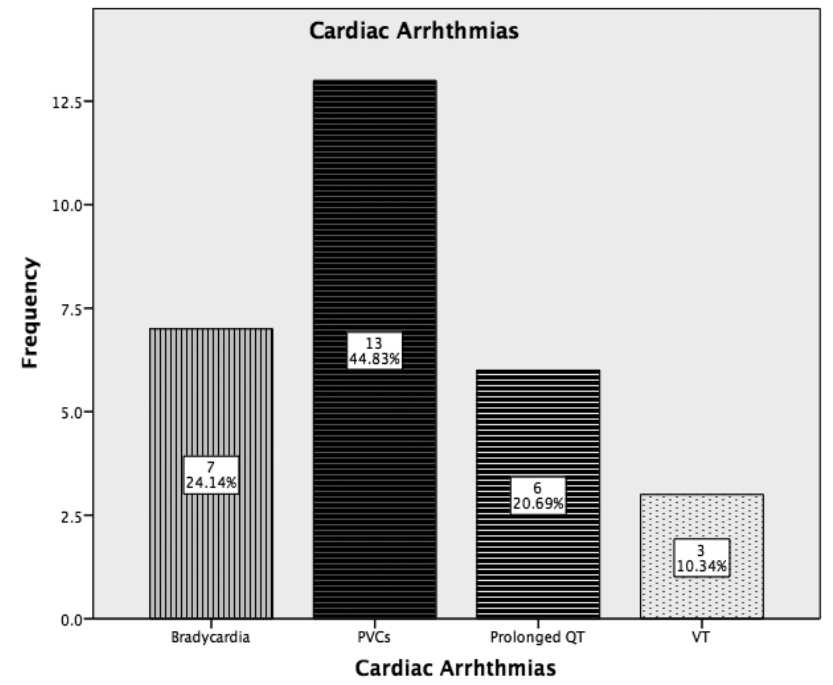

Figure-2. Cardiac arrythmias in OP poisnoning $n=29$.

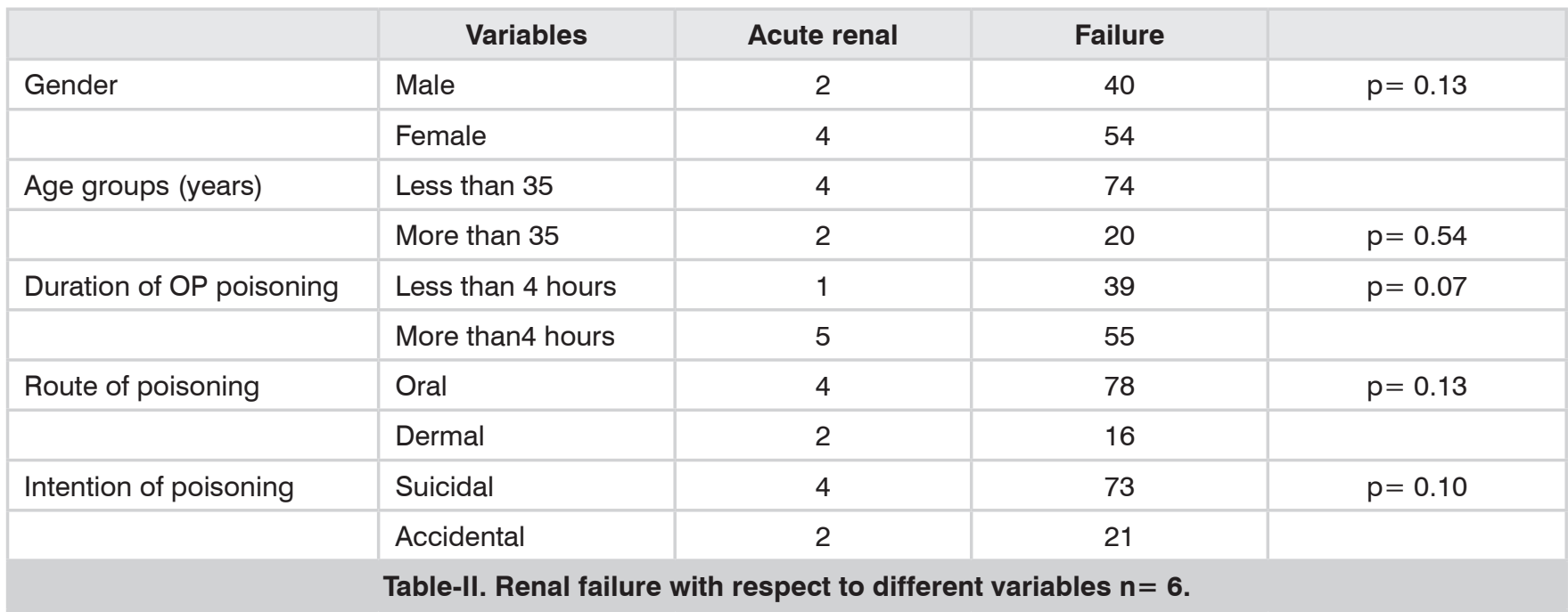

\begin{tabular}{|c|c|c|c|c|}
\hline & Variables & Cardiac & Complications & \\
\hline & & Yes & No & \\
\hline \multirow[t]{2}{*}{ Gender } & Male & 10 & 38 & $p=0.17$ \\
\hline & Female & 19 & 33 & \\
\hline \multirow[t]{2}{*}{ Age groups (years) } & Less than 35 & 22 & 56 & \\
\hline & More than 35 & 7 & 15 & $p=0.72$ \\
\hline \multirow[t]{2}{*}{ Duration of OP poisoning } & Less than 4 hours & 6 & 34 & $p=0.08$ \\
\hline & More than4 hours & 23 & 37 & \\
\hline \multirow[t]{2}{*}{ Route of poisoning } & Oral & 24 & 58 & $p=0.001$ \\
\hline & Dermal & 5 & 13 & \\
\hline \multirow[t]{2}{*}{ Intention of poisoning } & Suicidal & 27 & 46 & $p=0.001$ \\
\hline & Accidental & 2 & 25 & \\
\hline
\end{tabular}




\section{DISCUSSION}

Organophosphate (OP) compounds are widely used for insecticide purpose in developing world like Pakistan. Improper storage and easy availability has increased the risk of its access for suicidal intent and accidental exposure. Moreover poorly equipped dressing for sprays has also led to more accidental exposure via transdermal absorption.

In this study there was female predominance affecting $58 \%$ of cases. This was similar to a study by Faiz MS et al who also had more it in their study with a ratio of 1.5:1. ${ }^{13}$ Howe ever studies done by Tall et al had higher number in males. ${ }^{14}$ This can be due to the difference in mode of presentation in both studies. As in study by Tall et al, which was carried out at developed county and their majority of cases presented with transdermal spread due to accidental exposure as compared to oral intake as in our study.

Out of total 35 cases with complications, ARF was seen in 6 cases. However there was no significant association with any of the study variables. The higher number was seen in females and cases that presented after 4 hours of exposure. Similar was seen other studies. . $^{9,11,15}$ The reason of higher renal failure in females and specially presenting after four hours of toxicity can be a part of a single mechanism. The females in this study took OP compound orally in majority of cases and due to its suicidal intent, they might have taken higher doses and they also presented late as compared to accidental exposures. This led to a higher degree of its absorption and for a longer period of time which led to a higher complication rate in the form of renal failure. However, this difference was not found statistically significant.

Cardiac complications were seen in 29 out of 100 cases. These complication were again more common in females and significant association was seen with oral intake and with suicidal intention with $p=0.001$ and 0.001 . Similar was seen by other studies that also found almost similar percentages. ${ }^{12,16-17}$ The number was slightly higher in our study as compared to previous ones. The reason might be again the mode of exposure due to higher suicidal approach and oral intake in our study than accidental exposure in developed countries.

The reason of significant association of oral intake and suicidal intent with cardiac toxicity can be explained by the same rationale that the cases with suicidal intake took it orally and with higher doses and cardiac complications were commoner and higher than ARF because cardiac complications are one of the acute complications than ARF which might be avoided with early interventions. Secondly the number was also mimicked higher due to PVCs which was the most common but not life threatening. Thirdly atropine which is considered the mainstay of treatment also had arrythmogenic effect. Unfortunately, out of 29 cases with these complication 9 died in the hospital. Contrary to all that, as this is a remote area and dealing a large square are, and higher burden of the patients also led to delay in the diagnosis and then management which posed further burden in terms of its cardiotoxic effects.

There were few limitations too. As this study was conducted to see only the cardiac and renal complications and did not observe the other well reported events involving CNS, GIT and respiratory system. And due to higher burden of the suicidal cases, we were also unable to collect the data regarding the amount of OP taken to develop any dose response association.

\section{CONCLUSION}

OP poisoning is common and cardiac complications are more than acute renal failure. Oral intake and with suicidal intention are significantly associated with cardiac complications.

Copyright@ 21 Oct, 2019.

\section{REFERENCES}

1. Eddleston M. Patterns and problems of deliberate self-poisoning in the developing world. Quart J Med. 2000; 93:715-31.

2. WHO. Public health impact of pesticides used in agriculture. Geneva, Switzerland: World Health Organization; 1990. 
3. Gunnell D, Eddleston M, Phillips MR, Konradsen F. The global distribution of fatal pesticide self-poisoning: Systematic review. BMC Public Health 2007; 7:357.

4. Patel V, Ramasundarahettige C, Vijayakumar L, Thakur JS, Gajalakshmi V, Gururaj G, et al. Million death study collaborators. Suicide mortality in India: A nationally representative survey. Lancet. 2012; 379:2343-51.

5. Worek F, Kleine A, Falke K, Szinicz L. Arrhythmias in organophosphate poisoning: Effect of atropine and bispyridinium oximes. Arch Int Pharmacodyn Ther 1995; 329:418-35.

6. Tripathi S, Srivastav AK. Pesticide. Biochem Physiol. 2010; 97:60-65.

7. Poojara L, Vasudevan D, Arun Kumar A S, Kamat V. Organophosphate poisoning: Diagnosis of intermediate syndrome. Indian $\mathrm{J}$ Crit Care Med. 2003;7:94-102

8. Singh S, Sharma N. Neurological syndromes following organophosphate poisoning. Neurol India 2000; 48:308.

9. Kumar SV, Fareedullah, Sudhakar Y, Venkateswarlu B, Kumar EA. Current review on organophosphorus poisoning. Arch Appl Sci Res. 2010; 2(4):199-215.

10. Gaspari RJ, Paydarfar D. OP poisoning. Neurotoxicol. 2007; 28:664-671.
11. Ather NA, Ara J, Khan EA, Sattar RA, Durrani R. Acute organophosphate insecticide poisoning. J Surg Pak. 2008; 13:71-4.

12. Ludomirsky AH, Klein P, Sarelli B, Kiss, Z. Fazekas T. Arrhythmias and Q-T prolongation in organophosphate poisonings. Acta Cardiol. 1979; 34:323-30.

13. Faiz SM, Mughal S, Memon AQ. Acute and Late Complications of Organophosphate Poisoning. J Coll Phys Surg Pak. 2011; 21 (5):288-90.

14. Tall A, Ly AB, Nabeth P, Sall AA, Sarr FD, Faye J, et al. Epidemiological investigation of death cases by pesticide poisoning. J Agric Biotechnol Sustainable Develop. 2010; 2:51-5.

15. Cavari Y, Landau D, Sofer S, Leibson T, Lazar I. Organophosphate poisoning-induced acute renal failure. Pediatr Emerg Care. 2013; 29(5):646-47.

16. Malik GM, MubarikM, RomshooGJ. Organophosphorus poisoning in the Kashmir Valley, 1994-1997. N Engl J Med 1998; 338:1078-9.

17. Laudari S, Patowary BS, Sharma SK, Dhungel S, Subedi $\mathrm{K}$, Bhattacharya $\mathrm{R}$, et al. Cardiovascular effects of acute organophosphate poisoning. Asia Pac J Med Toxicol. 2014; 3:64-67.

\begin{tabular}{|c|c|c|c|}
\hline \multicolumn{4}{|c|}{ AUTHORSHIP AND CONTRIBUTION DECLARATION } \\
\hline Sr. \# & Author(s) Full Name & Contribution to the paper & Author(s) Signature \\
\hline 1 & M. Shoaib Akhtar & $\begin{array}{l}\text { Conception design, Review } \\
\text { approval. }\end{array}$ & \\
\hline 2 & Aziz Ur Rehman & $\begin{array}{l}\text { Acqusition \& analysis drafting } \\
\text { revision. }\end{array}$ & \\
\hline 3 & Kiran Akbar & Conception, design, approval. & \\
\hline 4 & Mazhar Hussain & Design, interpretation \& revising. & \\
\hline 5 & Moazzam Ali Atif & Acquisition, Analysis, draft \& & \\
\hline 6 & M. Shahbaz Hussain & Design, approval. & \\
\hline
\end{tabular}

